\title{
ELECTRODIALYSIS TECHNOLOGY FOR SALT RECOVERY FROM ALUMINUM SALT CAKE WASTE BRINES
}

\author{
G.K. Krumdick, D.J. Graziano, and J.N. Hryn \\ Argonne National Laboratory \\ 9700 South Cass Avenue \\ Argonne, Illinois 60439, U.S.A.
}

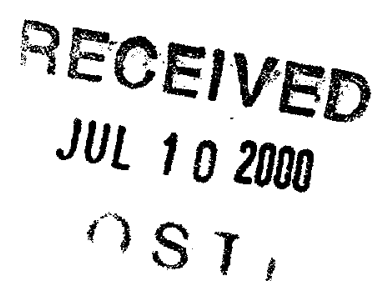

ABSTRACT

Electrodialysis technology is being developed to recover salt from brines generated in the commercial process for recycling aluminum salt cake. Salt cake, a waste stream from the aluminum industry, contains aluminum metal, salt $(\mathrm{NaCl}$ and $\mathrm{KCl})$, and nonmetallic impurities. After grinding and screening to separate out aluminum metal, salt cake solids are leached in water and filtered to recover a nonmetallic product (NMP). The filtered brine is then processed in an evaporator to separate salt and water. Researchers at Argonne National Laboratory identified electrodialysis as a promising process for salt recovery that may be less cost prohibitive than evaporation. Laboratory experiments suggested that the cost advantage of electrodialysis could be further improved through the selection of membranes to reduce power consumption and by operating with a differential pressure to reduce water transfer across the membranes. A large-scale electrodialysis pilot plant has been designed and constructed to verify laboratory results and the commercial viability of the process. Experiments are currently underway to characterize the effects of differential pressure, concentration difference, and current density on the water transfer and current efficiency of electrodialysis operations with concentrated brines.

The submitted manuscript has been created by the University of Chicago as Operator of Argonne National Laboratory ("Argonne") under Contract No. W-31-109-ENG-38 with the U.S. Department of Energy. The U.S. Government retains for itself, and others acting on its behalf, a paid-up, nonexclusive, irrevocable worldwide license in said article to reproduce, prepare derivative works, distribute copies to the public, and periorm pub iicly and display publicly, by or on behalt of the Government. 


\section{DISCLAIMER}

This report was prepared as an account of work sponsored by an agency of the United States Government. Neither the United States Government nor any agency thereof, nor any of their employees, make any warranty, express or implied, or assumes any legal liability or responsibility for the accuracy, completeness, or usefulness of any information, apparatus, product, or process disciosed, or represents that its use would not infringe privately owned rights. Reference herein to any specific commercial product, process, or service by trade name, trademark, manufacturer, or otherwise does not necessarily constitute or imply its endorsement, recommendation, or favoring by the United States Government or any agency thereof. The views and opinions of authors expressed herein do not necessarily state or reflect those of the United States Government or any agency thereof. 


\section{DISCLAIMER}

Portions of this document may be illegible in electronic image products. Images are produced from the best available original document. 


\section{INTRODUCTION}

Salt cake is a waste stream generated from the melting of aluminum drosses and lowgrade scrap in rotary furnaces that use salt fluxes to minimize oxidation of the aluminum and bind with impurities. It consists of entrained aluminum metal, spent salt fluxes (mainly $\mathrm{NaCl}$ and $\mathrm{KCl}$, with a small amount of $\mathrm{MgCl}_{2}$ and $\mathrm{CaCl}_{2}$ ) and an oxide-rich fraction called NMP (non metallic product) consisting primarily of alumina and spinel (1). We estimate that over one million tons of salt cake are landfilled annually in the United States. This volume is growing with the increased use and recycling of aluminum. A commercial alternative to landfilling is a treatment technology consisting of crushing and screening to recover the coarse aluminum metal fractions and leaching the remaining NMP to remove the salt. This process produces a salt brine waste stream. Our analysis indicates recovering the salts from the leach solution is the most energy and cost intensive unit operation in salt cake recycling (2).

Several alternate salt recovery processes were identified and compared to the evaporation process for technical feasibility and economics. The economic analysis indicated that, of the potential processes assessed, an electrodialysis-based technology might be the most cost effective (3). The capital cost of electrodialysis was estimated to be significantly less than that for evaporation, while the energy costs were significant, but comparable for the two technologies. Argonne National Laboratory have with its industrial partner Alumitech, Inc. have undertaken a research project to develop a cost effective electrodialysis process for this application.

\section{BACKGROUND}

Electrodialysis (ED) is a separation process in which salt is transferred from a salt depleted stream (diluate) to a salt concentrated stream (concentrate) under the driving force of an electrical potential gradient. In the ED stack, diluate and concentrate solutions are pumped through individual cells separated by alternating cation and anion selective membranes. Ions migrate from the diluate cells to the concentrate cells through the ion-selective membranes when DC current is applied to the stack. Separate compartments, flushed by an electrode rinse solution, isolate the electrodes.

The integration of electrodialysis into the salt cake recovery process is depicted in Figure 1. Salt is leached from salt cake, transferred by electrodialysis from the filtered salt cake leach solution (diluate stream) to a salt-saturated solution (concentrate stream), and recovered by solid/liquid separation. Filtered salt cake leach solutions contain primarily chloride salts $\left(\mathrm{NaCl}, \mathrm{KCl}\right.$ and a small amount of $\mathrm{MgCl}_{2}$ and $\mathrm{CaCl}_{2}$ ) at a concentration ranging from 10-22 wt\%. In the ED stack, the mixed salts are concentrated to the point of saturation (33-35wt\% salt) and precipitated out in the concentrate stream. 


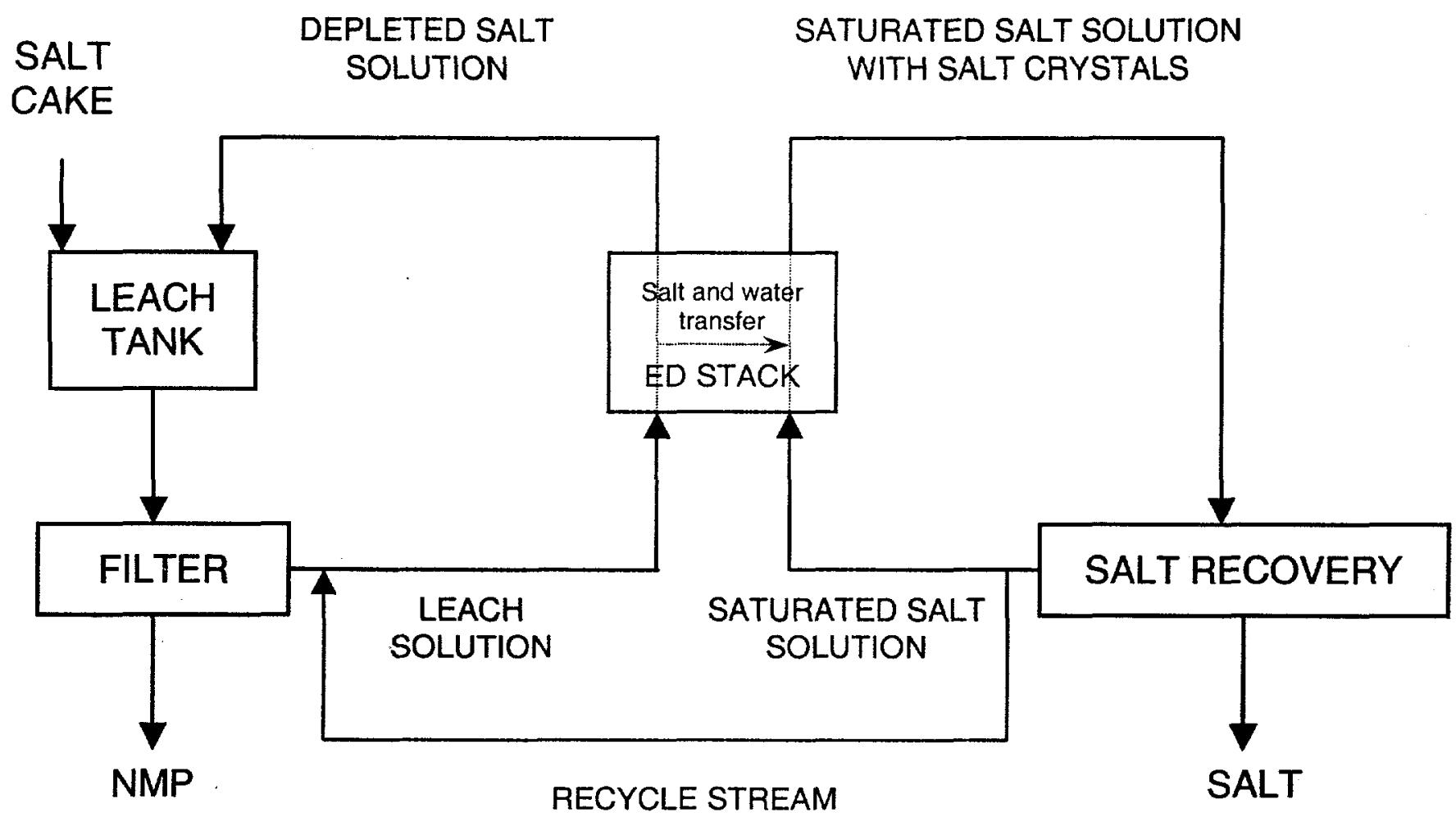

Figure 1 - Electrodialysis-based process for salt recovery from salt cake leach solutions.

The recycle stream shown in Figure 1 is included to balance water in the system. In aqueous solutions, ions are surrounded by a hydration shell of water molecules. In ED, ions migrating through the membranes carry water with them in the hydration shell $(4,5)$. Water is also transferred across the membranes by osmosis when a concentration difference exists between the diluate and concentrate solutions. This water transfer reduces the effectiveness of ED in concentrating the product brine and, at a high enough rate, obstructs the generation of solids.

Our objectives for the laboratory bench-scale tests were to determine conditions for the minimization of water transfer to promote the generation of salt, to evaluate different membranes for effectiveness and to determine the electrode rinse solution. Results from the bench scale experiments provided the design platform for the large-scale pilot plant. Goals for the pilot plant are to verify laboratory data and to demonstrate commercial-scale operations. 


\section{LABORATORY}

\section{Experimental}

The bench-scale system utilized a Tokuyama ED stack, model TS2-5. The ED stack contains five cell pairs with membrane area of $0.02 \mathrm{~m}^{2}$. Membranes studied were Tokuyama Soda's Neosepta AMX, AM1, CMX, CMS and CM1, Asahi's ASO, CMO and CSV, and Raipore's R4010 and R4030. Electrode rinse solutions tested were $\mathrm{NaOH}(5 \mathrm{wt} \%), \mathrm{Na}_{2} \mathrm{SO}_{4}$ (10.8 wt\%) and $\mathrm{NaNO}_{3}(5 \mathrm{wt} \%)$. Concentrate and diluate solutions were prepared using reagent-grade $\mathrm{NaCl}$ and $\mathrm{KCl}$. Diluate solutions were also prepared using industrial salt cake leach solutions. Concentrate solutions were near saturation while diluate solutions varied from 12 to $22 \mathrm{wt} \%$.

The laboratory unit was equipped with inline instruments for monitoring the following: diluate, concentrate and electrode rinse feed rates and tank temperatures; diluate and concentrate feed conductivities and pressures; and voltages at the power source, across the stack (including anode and cathode chambers), and across the five cell pairs. The DC rectifier supplied power to the ED stack at constant current. A differential pressure between the concentrate and the diluate compartments was introduced by restricting concentrate return flow.

Before each experiment, the ED unit was thoroughly cleaned with distilled water and drained. Test solutions were added to the tanks and allowed to circulate through the unit for five minutes at high flow rates. The diluate and concentrate feed rates were then set to 1.6 liters/hour. Current was turned on to yield the current density specified for the test. Experiments typically lasted four hours, during which time the temperatures of solutions steadily increased and voltages decreased. Solution concentrations were monitored on-line by conductivity meters. At discrete time intervals, samples were collected for analyses. At the end of an experiment, the volumes and densities of the diluate and concentrate solutions were measured. Current density and water transfer rates were calculated from the measured change in solution volume and concentration.

Results

The performances of a variety of membrane pairs were evaluated in the laboratory ED stack. A key performance indicator was the voltage drop across the ED stack caused by the resistances of the solutions and membranes. Selected results can be seen in Table I. Typically, membranes with the lowest published resistance provided the lowest voltage drops. The voltage drop was found to be independent of solution concentration and flow rate, due to the high salt concentrations. Membrane pairs providing the lowest voltage drop per cell would yield the lowest power consumption operation and hence be most desirable. Mechanical strength of the membranes also has to be considered, however, particularly in light of the differential pressure operation. Consequently, a trade off has to be made between robustness and power consumption. AM1/CMX membranes were chosen as the membranes for the pilot plant system. 
Table I - Laboratory Experimental Results - Membrane Testing

(Tests conducted with solutions of $25 \mathrm{wt} \% \mathrm{NaCl}, 27$ amps. Voltages measured at $40^{\circ} \mathrm{C}$.)

\section{Membrane Pair anion/cation}

$\begin{array}{ll}\text { R4010-R4030 } & 0.40 \\ \text { AM1-CM1 } & 0.50 \\ \text { AFN-CM1 } & 0.50 \\ \text { ASO-CMO } & 0.53 \\ \text { AMX-CMO } & 0.56 \\ \text { ASO-CMS } & 0.59 \\ \text { ACS-CMS } & 0.61 \\ \text { AMX-CMX } & 0.86 \\ \text { ASO-CSV } & 1.05 \\ \text { ACM-CMS } & 1.56\end{array}$

\section{Volts/Cell}
0.40
0.50
0.56
0.59
0.61
1.05
1.56

At the vendor's recommendation, a $5 \% \mathrm{NaOH}$ solution was used for the electrode rinse during initial testing with the laboratory ED stack. Operations with the $\mathrm{NaOH}$ electrode rinse solutions worked out well; however, the $\mathrm{pH}$ of the diluate and concentrate solutions steadily increased throughout an experiment. We were concerned that $\mathrm{Mg}$ and $\mathrm{Ca}$ in the salt cake leach solutions would form insoluble hydroxides in the stack with the $\mathrm{NaOH}$ electrode rinse solution (6). Spiking studies with $\mathrm{Mg}$ and $\mathrm{Ca}$ chloride salts confirmed this phenomenon. Consequently, we evaluated alternative electrode rinse solutions, specifically: $\mathrm{Na}_{2} \mathrm{SO}_{4}(10.8 \mathrm{wt} \%)$ and $\mathrm{NaNO}_{3}$ (5 wt\%). The $\mathrm{Na}_{2} \mathrm{SO}_{4}$ solutions provided only minor improvement, likely because of $\mathrm{CaSO}_{4}$ insolubility. Operations with the $\mathrm{NaNO}_{3}$ electrode rinse solution were better, but a steadily increasing $\mathrm{pH}$ in all solutions eventually caused precipitation. We found, however, that the $\mathrm{Mg}$ and $\mathrm{Ca}$ hydroxide precipitation problem could be eliminated with $\mathrm{NaNO}_{3}$ solutions neutralized with nitric acid to maintain a $\mathrm{pH}<9$.

A final major initiative in the laboratory testing was to explore techniques for reducing the water transfer rate (moles water/mole salt transferred) across the membranes. Earlier studies had shown that $\mathrm{NaCl}$ and $\mathrm{KCl}$ salts could be precipitated in the concentrate stream by electrodialysis (7). In these tests, salts were precipitated only when the concentration difference between the diluate and concentrate was kept low (ranging from 0-10 wt\% during an experiment). The capability to saturate the concentrate solution to the point of precipitation is dependent on the amount of water transferred from the diluate to concentrate solutions. The overall water transfer was shown to have an osmotic component directly proportional to the concentration difference (7). In the commercial application, the concentration difference between the diluate and concentrate is expected to be in the range of $15-25 \mathrm{wt} \%$. Consequently, research was undertaken to develop methods for reducing the water transfer across the membranes.

The concept of applying a differential pressure between the concentrate and diluate cells to minimize osmotic water transfer was proposed and tested with promising results. Applications of relatively small differential pressures (0-20 psi) were found to impact the water transfer rate. Water transfer rate decreased consistently with increasing differential pressure. Accompanying the decrease in water transfer rate, however, was a decrease in current efficiency. These trends are shown in the results displayed in Figures 2 and 3. 


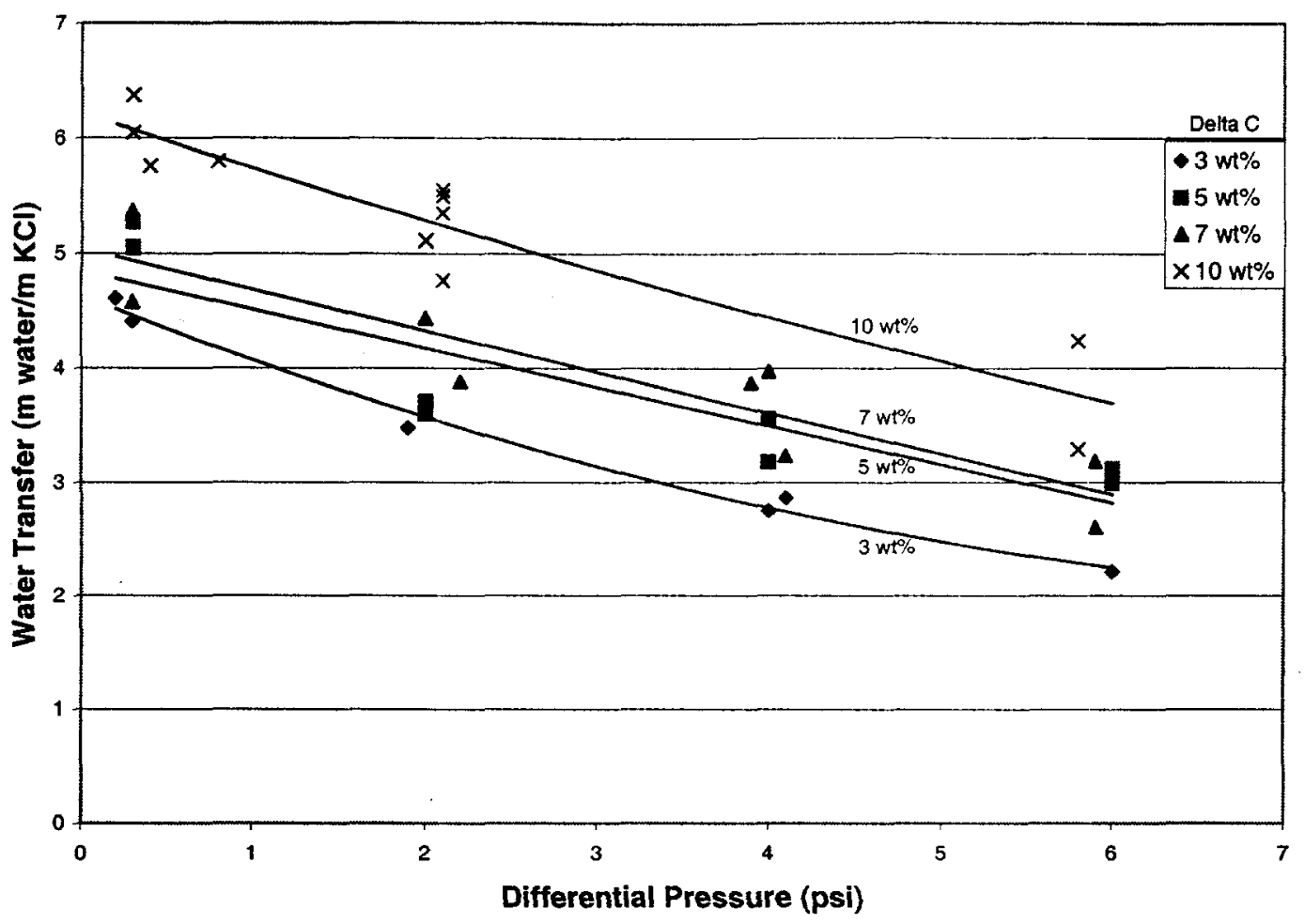

Figure 2-Effect of differential pressure on water transfer observed in laboratory tests.

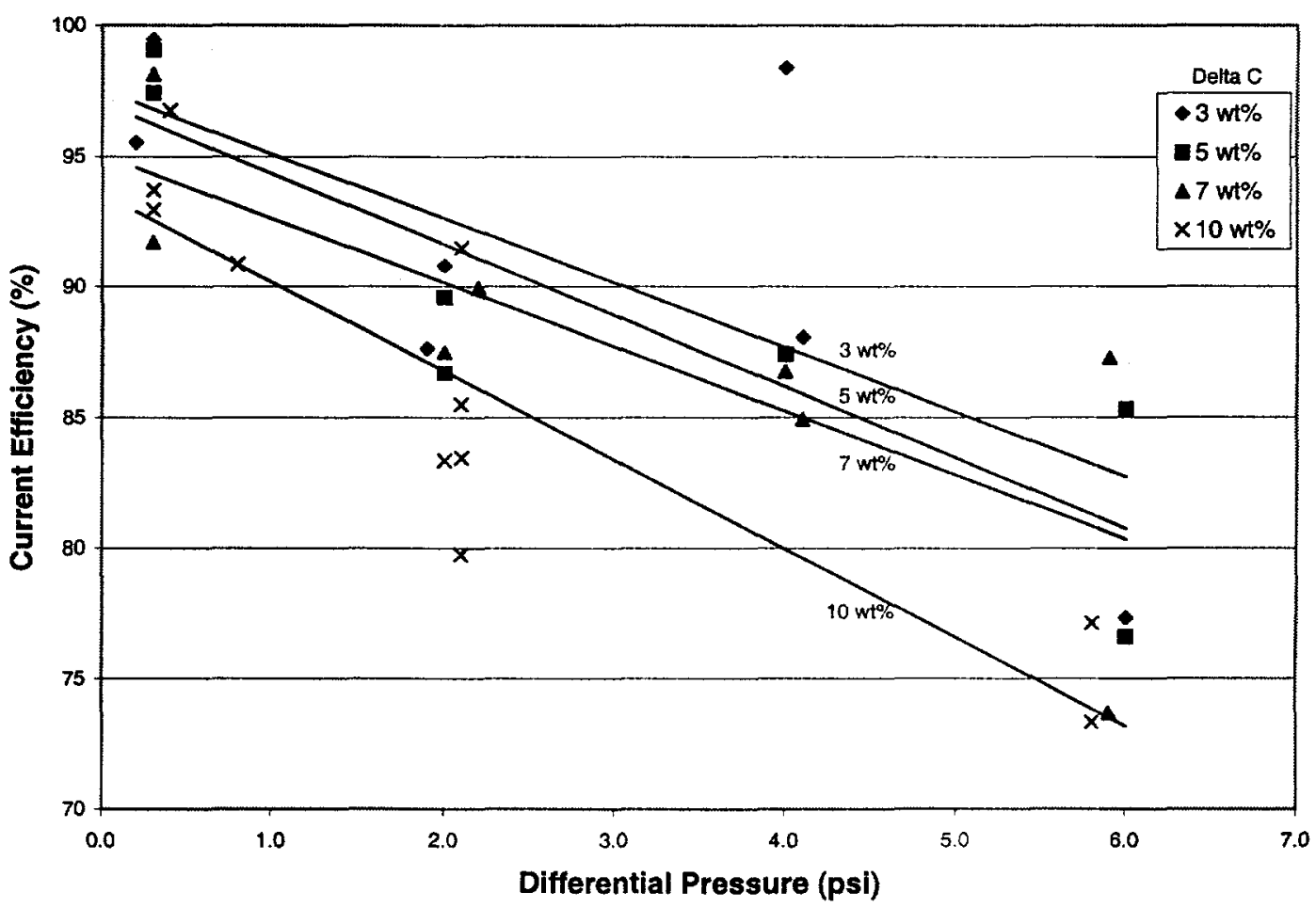

Figure 3. - Effect of differential pressure on current efficiency observed in laboratory tests. 


\section{PILOT PLANT}

A pilot plant was constructed at ANL in 1999-2000 to evaluate the application of electrodialysis (ED) to the recovery of salts from concentrated brines. A photograph of the unit appears in Figure 4. The pilot plant is equipped with a commercial scale ED stack served by computer-monitored-and-controlled diluate, concentrate and electrode rinse solution loops. Although designed specifically for the salt recovery application, the pilot plant is seen as a great asset for future projects involving electrodialysis. All equipment, instrumentation and piping in contact with the process are made of non-corrosive materials that will accommodate a wide range of solutions. The piping is schedule $80 \mathrm{PVC}$ and can be easily modified or rerouted.

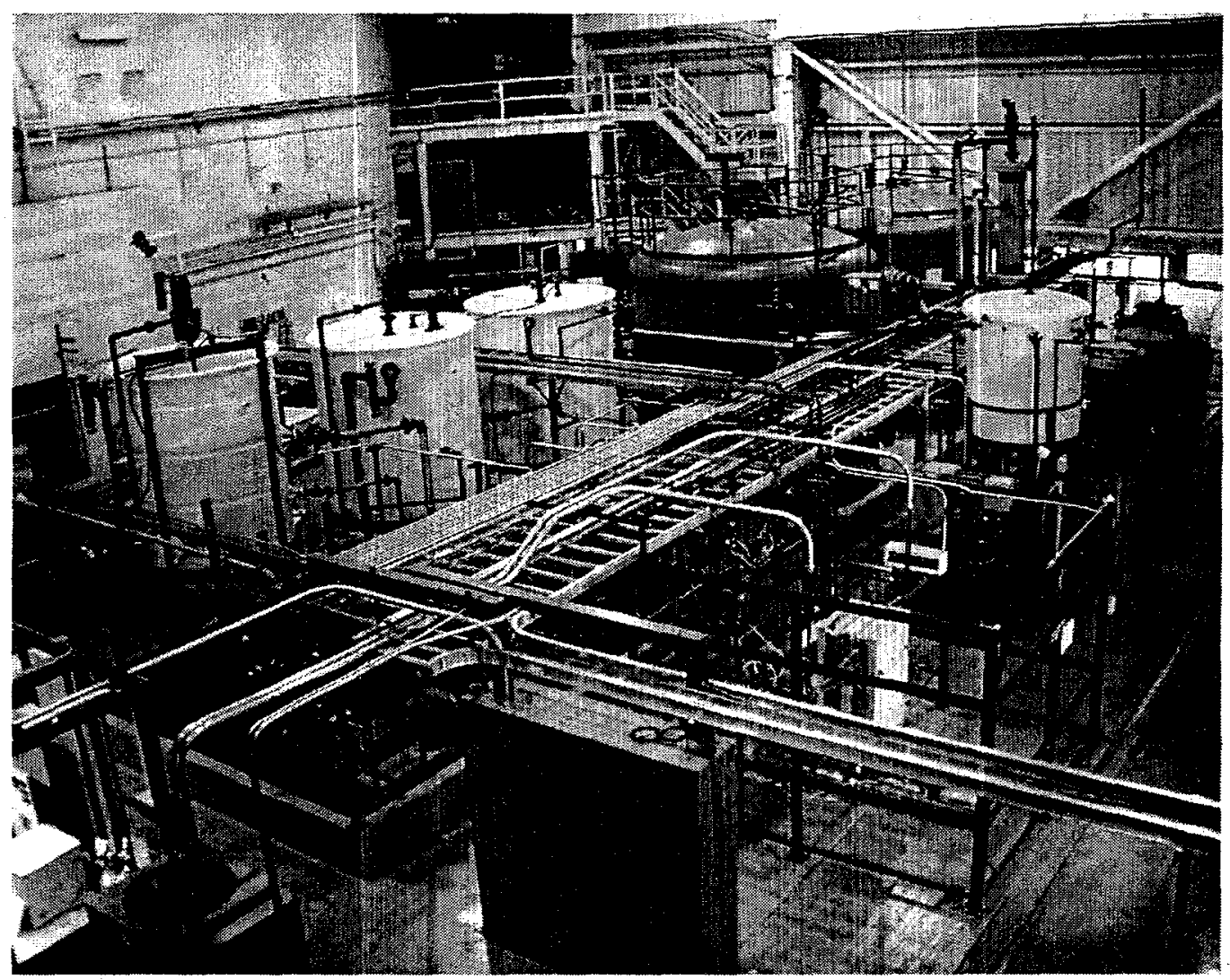

Figure 4 - Electrodialysis Pilot Plant

\section{Design Features}

The objectives of the pilot plant scale testing are to (i) verify the effects of differential pressure observed in the laboratory scale testing; (ii) determine if solids can be generated and processed in a commercial scale ED stack; and (iii) assess long-term operability of the process. To achieve these objectives, several unique features were incorporated into the pilot plant design.

The capability to evaluate the effect of differential pressure (from 0-30 psi) between the concentrate and diluate cells on ED performance was realized through the selection and design 
of the ED stack and instrumentation. The Eurodia EUR-40-76-5 stack selected for the pilot plant had the highest pressure rating ( $5 \mathrm{bar}, 75 \mathrm{psig}$ ) of commercially available equipment. The high pressure rating is important to accommodate the inlet pressure of the concentrate feed during tests at the high limit of differential pressure. The five non-active cells (included to distribute current from rod electrodes) and cells next to the electrode rinse chambers in the Eurodia EUR-40-76-5 stack are configured to carry diluate solution that will be closer in pressure to the electrode rinse streams.

The pilot plant also needed to be designed to monitor and control the differential pressure between the concentrate and diluate cells. Mass flow feed rates of the diluate and concentrate are measured by Coriolis meters and controlled with individual pneumatic control valves. The inlet pressures of the diluate and concentrate feeds are monitored but not controlled. The pressure of the diluate return stream and differential pressure between the concentrate and diluate return streams are measured and controlled by individual pneumatic control valves. The three pressure and one differential pressure instruments are installed as close as possible to the inlets and outlets of the ED stack. They are specially designed to be electrically resistant, with no metal parts in contact with the fluid. The differential pressure controller (operating on the differential pressure between the concentrate and diluate return streams) is employed for testing at varying differential pressures. For testing from 0-4 psi differential pressure, the back pressure controller on the diluate return stream is used to compensate for the higher downstream pressure of the concentrate loop.

To verify the laboratory observations on the effects of differential pressure, the pilot plant had to be designed to generate data required to calculate current efficiency and water transfer in the ED stack. The effects of differential pressure were to be tested initially on single salt solutions $(\mathrm{NaCl}$, then $\mathrm{KCl})$, then dual salt solutions $(\mathrm{NaCl}$ and $\mathrm{KCl})$, and finally on industrial salt cake brines ( $\mathrm{NaCl}, \mathrm{KCl}$ and impurities). At the test concentrations of the diluate and concentrate brines ( $12 \mathrm{wt} \%$ up to saturation), density provides a preferred measure (versus conductivity) of $\mathrm{NaCl}$ or $\mathrm{KCl}$ concentration.

Coriolis meters that provide accurate measure of the mass flow, density and temperature of a process stream are installed in the diluate feed and return streams and in the concentrate feed stream. The diluate and concentrate tanks are mounted on load cells. For tests with single salt solutions (i.e. $\mathrm{NaCl}$ or $\mathrm{KCl}$ only), the current efficiency and water transfer can be derived from material balance calculations around the diluate and concentrate tanks using initial and ending tank weights and solution densities.

The second objective of the pilot plant testing is to determine if solids can be generated and processed in a commercial scale ED stack. The Eurodia EUR-40 stack is a commercial size ED stack -- the largest available from this vendor at the time of purchase. A typical commercial EUR-40 stack would be equipped with hundreds of cell pairs. The pilot plant EUR-40-76-5 stack has 76 active cell pairs. Plugging problems associated with solids would be expected to occur in the inlet and outlet ports of individual cells, or between the membranes - independent of the number of cell pairs in the stack. Consequently, if successful operations with solids can be demonstrated with the EUR-40-76-5 stack in the pilot plant, they should also be realizable in a commercial plant.

Eurodia engineers specially designed the cell spacers for our application. The concentrate cell spacers are thicker than the diluate cell spacers ( 0.6 and $0.4 \mathrm{~mm}$, respectively) The inlet and outlet ports for the concentrate cells are narrower than for the diluate cells (11 vs. $22 \mathrm{~mm}$, respectively) to increase velocity through them. 
Features included in the pilot plant for operations with solids include: clear piping runs for visual observation of solids; diluate and concentrate piping manifolded to allow upflow or downflow through the ED stack; cooler installed in the concentrate return loop to crystallize out solids from saturated solutions; and concentrate tank design w/ mixer to allow salts to settle or to be slurried.

The pilot plant was designed to accommodate both short term $(<12$ hrs $)$ batch tests to investigate process variable effects and longer term continuous tests to investigate operability and membrane life. The diluate and concentrate tanks are oversized to dampen the effects of concentration change on results. During batch runs, the concentrations in both tanks change slowly, allowing results to be obtained at near constant concentration conditions. For continuous operations, a variable speed pump is installed to transfer brine or a slurry of salt crystals and brine from the concentrate tank to the diluate tank.

\section{Equipment}

The heart of the pilot plant is the electrodialysis system. In this system, salts $(\mathrm{NaCl}$ and $\mathrm{KCl})$ are transported from a dilute brine or diluate $(10-25 \mathrm{wt} \%$ salts) into a saturated brine or concentrate (25-35 wt\% salts) by the current-assisted transfer of ions $\left(\mathrm{Na}^{+}, \mathrm{K}^{+}\right.$and $\mathrm{Cl}$ ) through anion- and cation-selective membranes. The diluate and concentrate brines are recirculated continuously through dedicated cells in the electrodialysis stack. Electrode rinse solution is circulated through the anode, cathode and mid chambers of the ED stack to purge accumulating ions and gases in these chambers. Operations have been demonstrated with two electrode rinse solutions: (i) $\mathrm{NaOH}$ at $2-5 \mathrm{wt} \%$ concentration and (ii) $\mathrm{NaNO}_{3}$ at $5 \mathrm{wt} \%$ concentration and $\mathrm{pH}$ of 7-9.

The ED stack was supplied by Eurodia. The stack, EUR-40-76-5, contains 76 active cell pairs and is equipped with membranes of $0.4 \mathrm{~m}^{2}$ effective area. The cation membranes are Neosepta CMX and anion membranes are Neosepta AM1. The stack was supplied with three sets of rod electrodes: (i) nickel anodes and cathodes for operations with $\mathrm{NaOH}$ electrode rinse solution; (ii) DSA/iridium coated anodes and graphite cathodes for operations with $\mathrm{NaNO}_{3}$ electrode rinse solution; and (iii) DSA/ruthenium coated anodes and graphite cathodes for electrode rinse solutions containing $\mathrm{HCl}$. Power is supplied to the ED stack by a Rapid Power DC rectifier specified to provide up to 575 amps and 100 volts (changeable to 210 volts). Platinum wire probes are installed in the ED stack near the cathode, anode and both sides of the mid electrode chamber, and at cells $14,28,52$ and 66 to allow monitoring of voltages across the stack.

The ED diluate loop consists of a 1500-gallon HDPE feed tank, Vantom model CGPY800 centrifugal feed pump, mass feed rate and back-pressure control, and instrumentation to monitor mass flow rates, densities, temperatures and pressures. The feed tank is mounted on a weigh scale and equipped with an ultrasonic level transmitter.

Similarly, the ED concentrate loop consists of a 1250-gallon HDPE feed/salt settling tank, Vantom model CG-PY800 centrifugal feed pump, mass feed rate and differential pressure control, and instrumentation to monitor mass flow rates, densities, temperatures and pressures. The concentrate loop also is equipped with a plate and frame exchanger cooled by chilled water. The feed tank is mounted on a weigh scale and equipped with an ultrasonic level transmitter. The tank has an installed mixer and a bottom fed slurry pump for continuous operation with solids. 
The electrode rinse loop contains a 500-gallon HDPE feed tank, March model TE-8KMD feed pump, manual anolyte and catholyte flow rate adjustment, instrumentation to monitor flow rates, pressures and temperatures, and hydrogen purge equipment. A small amount of hydrogen gas $(\max 0.16 \mathrm{CFM})$ is generated at the cathode and oxygen gas (max $0.08 \mathrm{CFM}$ ) at the anode. To prevent the mixing of these gases, the hydrogen is removed from the catholyte by bubbling nitrogen through retained solution. The diluted hydrogen gas is vented through an FRP blower to atmosphere. The electrode rinse tank is equipped with an ultrasonic level indicator and $\mathrm{pH}$ probe.

Other systems in the pilot plant are dedicated to the storage and periodic preparation and handling of commercial, prepared, and waste brines. Pilot plant control alarms, shutdowns and safety interlocks are handled by a dual computer control and data acquisition system.

\section{Data Acquisition System}

To provide advanced instrumentation and data acquisition without compromising a reliable control system, an integrated, dual stage supervisory control and data acquisition system (SCADA) was developed. The hardware interface consists of an Allen-Bradley SLC $5 / 05$ system running parallel to a National Instruments FieldPoint system. The SLC, interfaced with RSView32, provides robust system's control and safety interlock capabilities, while the FieldPoint system, when interfaced with BridgeView software, allows for advanced data acquisition. Seamless integration between systems is achieved utilizing Object Linking and Embedding for Process Control (OPC) Servers, linked over Ethernet. This design allows for the SLC to handle plant operations (pump control, PID loops, and safety interlocks) while BridgeView is dedicated to data acquisition.

Complete facility operations are controlled through the SLC. Flow, pressure, and temperature parameters for PID loops are entered through the HMI using RSView32. Facility interlocks are also monitored by the SLC. Multi-level system shutdowns are initiated upon upset conditions to insure operator safety and equipment protection. Using OPC servers, SLC data common to both operations and data acquisition can be accessed by BridgeView. All critical systems are monitored and recorded by BridgeView. Data from instrumentation surrounding the ED concentrate and diluate flow loops are particularly important for material balances to determine water transfer and current efficiency.

$\underline{\text { Results }}$

We began testing in the pilot plant with $\mathrm{NaOH}(2-5 \mathrm{wt} \%)$ for the electrode rinse solution because our initial test solutions did not contain $\mathrm{Mg}$ and $\mathrm{Ca}$. Hydroxide ion permeation across the electrode rinse membranes, however, rapidly contaminated the concentrate and diluate solutions, increasing their $\mathrm{pH}$ to 11-12. High $\mathrm{pH}$ solutions can be detrimental to the life of the polyester spacers and AM1/CMX membranes installed in the ED stack. Consequently, we decided to operate with the $5 \mathrm{wt} \% \mathrm{NaNO}_{3}$ solution as tested in the laboratory. During initial tests with the $\mathrm{NaNO}_{3}$ electrode rinse, the $\mathrm{pH}$ of all solutions steadily increased. We believe the increase in $\mathrm{pH}$ was due to the formation of ammonia, which was detected in the headspace of the electrode rinse tank. To maintain the $\mathrm{pH}$ of the $\mathrm{NaNO}_{3}$ electrode rinse below 9, we installed a nitric acid metering pump system to continuously neutralize the solution. 
With the development of an acceptable electrode rinse system, pilot plant experimentation is currently underway. Bench-scale work is being verified. Water transfer versus differential pressure correlations are being determined, as well as their relation to current density and current efficiency. The operational effects of precipitation of solids in the concentrate stream are also being examined. Results will be presented at the TMS symposium held in Pittsburgh this October.

\section{CONCLUSION}

Experiments were performed on a lab scale and data were obtained to establish operating parameters and components for a large-scale electrodialysis plant. Membranes for economical salt recovery were identified. An electrode rinse solution was selected on the basis of performance. A significant correlation linking differential pressure between the concentrate and diluate and the total water transfer between the membranes was determined. Solutions were able to be concentrated to the point of precipitation and solids were formed. Lab results were promising enough to warrant the construction of a pilot scale electrodialysis plant.

The large-scale pilot plant provides us with the tools needed to verify the lab results on a commercial scale and to determine if the process is economically viable. The pilot plant was built with experimentation in mind and has the instrumentation and flexibility of a laboratory system. The planned testing will provide us with comprehensive data on the process to make the determination if the salt recovery technology can be successfully implemented by industry.

\section{ACKNOWLEDGEMENT}

This work is supported by the U.S. Department of Energy, Assistant Secretary for Energy Efficiency and Renewable Energy, under contract W-31-109-Eng-38.

\section{REFERENCES}

1. J.N. Hryn, E.J. Daniels, T.B. Gurganus, and K.M. Tomaswick, "Products from Salt Cake Residue-Oxide," Third International Symposium on Recycling of Metals and Engineered Materials, P.B. Queneau and R.D. Peterson, Eds., Warrendale, PA.: TMS, 1995, 905-916.

2. B.J. Jody, E.J. Daniels, P.V. Bonsignore, and D.E. Karvelas, "Recycling of Aluminum Salt Cake," Journal of Resources Management and Technology, Vol. 20, 1992, 38-49.

3. D. Graziano, J.N. Hryn, and E.J. Daniels, "The Economics of Salt Cake Recycling," Light Metals 1996, W. Hale, Ed. Warrendale, PA.: TMS, 1996, 1255-1260.

4. M. Rakib, Ph. Mocoteguy, Ph. Viers, E. Petit, and G. Durand, "Behaviour of Nafion 350 membrane in sodium sulfate electrochemical splitting: continuous process modeling and pilot scale tests" Journal of Applied Electrochemistry, Vol. 29, 1999, 1439-1448. 
5. J.W. Blackburn, "Electrodialysis Applications for Pollution Prevention in the Chemical Processing Industry”, J. Air \& Waste Manage. Assoc. Vol. 49, 1999, 934-942.

6. L. Summers, "Desalination Processes and Performance", Report LLNLUCRL-ID120367, 1995, Lawrence Livermore National Laboratory.

7. K. Sreenivasaro, F. Patsiogiannis, and J.N. Hryn, "Concentration and Precipitation of $\mathrm{NaCl}$ and $\mathrm{KCl}$ from Salt Cake Leach Solutions by Electrodialysis," Light Metals 1997, R. Huglen, Ed. Warrendale, PA.: TMS, 1997, 1153-1158. 